\title{
Les llegendes sobre el naixement i la infantesa de Jesús a la tradició catalana
}

\author{
Caterina Valriu Llinàs \\ Universitat de les Illes Balears \\ c.valriu@uib.cat
}

\begin{abstract}
RESUM
A la tradició catalana hi ha un gran nombre de llegendes que tracten del naixement $i$ la infantesa de Jesús i que s'articulen entorn d'episodis dels evangelis. L'estudi revisa més de I5o d'aquests relats provinents de diversos indrets del domini lingüistic, els confronta amb les informacions que aporten els evangelis, n'analitza els personatges principals, les estructures narratives, els aspectes literaris, les funcions que acompleixen en el context social, la ideologia que vehiculen i la seva intencionalitat moral. Finalment, es constata l'abundància $i$ varietat de materials, la relació amb les creences religioses $i$ màgiques, la funcionalitat estructural i ideològica i la seva importància en el context dels gèneres narratius orals així com en l'imaginari col-lectiu.
\end{abstract}

PARAUles CLAU

llegenda etiològica; evangelis; creença; flora; fauna

\begin{abstract}
The Catalan folklore tradition contains a large number of legends dealing with the birth and childhood of Jesus which are organised around episodes from the Gospels. This study reviews more than 150 of these stories from different parts of the Catalan linguistic area, compares them with the information provided in the Gospels, and analyses the main characters, narrative structures, literary aspects, the functions they perform in the social context, the ideology they espouse and their moral intent. Finally, the study confirms the abundance and variety of stories, the relationship between the stories and religious and magical beliefs, their structural and ideological functionality and their importance in the context of oral narrative genres and in the collective imagination.
\end{abstract}

KEYWORDS

Aetiological legend; gospels; belief; flora; fauna

REBUT: 29.II.2OI4 | ACCEPTAT: I5.I2.2OI4

Estudis de Literatura Oral Popular, núm. 4, 2OI5, I2I-I39 | DOI: IO.I7345/elop2OI5I2I-I39

ISSN: 2OI4-7996 | http://revistes.urv.cat/index.php/elop 


\section{Presentació ${ }^{1}$}

En els corpus llegendaris dels països de tradició cristiana, són habituals els relats que es relacionen amb les Sagrades Escriptures, tant de l'Antic com del Nou Testament. Sovint es tracta de petites narracions que glossen aspectes puntuals o marginals del que s'hi explica i els desenvolupen d'una manera poètica o bé són tradicions paral-leles que comparteixen amb la Bíblia episodis i personatges però que creen nous arguments que no apareixen en el Llibre Sagrat. D'entre aquest conjunt de materials narratius en destaquen molt especialment els relacionats amb la vida de Jesús, que se centren en els dos episodis cabdals de la seva biografia: el naixement i la mort. Atesa la gran quantitat de materials orals arreplegats entorn de la suposada trajectòria vital de Jesús, en aquest estudi ens centrarem en el grup de llegendes que situen la seva acció entorn de la Sagrada Família, el naixement i la infantesa; deixarem les de la passió i mort de Jesús per a un estudi posterior.

\section{Fonts i contextualització dels materials}

La revisió dels reculls de narrativa oral en llengua catalana publicats fins ara ens aporta una gran quantitat de material sobre el tema objecte del nostre estudi. Hem reunit I55 relats, la majoria dels quals (en concret, I38) foren recollits pel folklorista català Joan Amades a les primeres dècades del s. XX i publicats el 1950 en el context de la seva extensa obra titulada Folklore de Catalunya. La presència d'aquests tipus de llegendes en els altres reculls consultats és molt menor. Així, a la Catalunya del Nord, Esteve Caseponce (I972: I75-I8I) en recull una i vinculada tangencialment amb el naixement de Jesús; a la zona pirinenca, Pep Coll (I993: 307-308) n'aporta també una i Jordi Pere Cerdà (I96I: 45-50) una altra; Artur Quintana (I979: I6I) en recull dues a la Franja d'Aragó; Sara Llorens (I929: S. n.) dues més que provenen de la zona d'Alacant i del mateix indret n'aporta una el folklorista Joaquim Gonzàlez (I993: I25-I26). A Mallorca, Antoni M. Alcover en publica quatre dins la seva extensa col-lecció titulada Rondaies Mallorquines (I936-72, tom 5), Andreu Ferrer n'inclou tres en el seu llibre Llegendes de les Balears (2009: 295-297). També tres provenen d'Eivissa, del recull de Joan Castelló (2004: 38-42) i no en trobem cap en els corpus menorquins publicats. ${ }^{2}$

Aquestes dades resulten sorprenents pel que fa a les aportacions d'Amades, sobretot si tenim en compte que els anys de recol-lecció de materials per part de Joan Amades, Antoni M. Alcover, Andreu Ferrer, Sara Llorens i Esteve Caseponce són gairebé els mateixos, atès que pràcticament tots els relats foren documentats en terres de llengua catalana a la primera meitat del s. xx. Els altres reculls —els de Joan Castelló, Artur Quintana, Pep Coll i Joaquim Gonzàlez- són compilats a la segona meitat del s. Xx i, per tant, més recents, la qual cosa ens podria fer pensar que són narracions que - per les seves característiques funcionals i argumentalshan desaparegut en pocs anys dels repertoris orals dels nostres narradors. Però continuem sense tenir una explicació satisfactòria que justifiqui la gran abundàn-

I. Aquest article forma part del projecte «La literatura popular catalana en la segona meitat del s. XX: documentació, estudi i difusió» (FFI 20I2-3I808) finançat pel Ministerio de Economía y Competitividad.

2. Per a la referència i el títol de cada una d'aquestes llegendes, vegeu la bibliografia adjunta al final d'aquest article. 
cia de materials aportats per Amades en comparació amb els altres folkloristes. A partir d'unes cartes del folklorista alemany Walter Anderson a Joan Amades datades els anys I957-58 (Oriol 20I3: 66-67 i 74-75), sabem que Amades tenia la intenció de classificar el seu llegendari etiològic — tan extens i divers - i demanava ajut i assessorament a Anderson, el qual el posava al corrent dels diversos sistemes de classificació que aleshores eren usats pels folkloristes europeus. ${ }^{3}$ Aquesta tasca no es va arribar a enllestir, atès que Amades va morir el I959. Tanmateix, la voluntat d'ordenació i classificació no ens dóna la clau que expliqui la gran abundància de materials d'aquest estil que va recopilar, però sí que ens aporta algun indici sobre l'interès d'Amades cap a les llegendes etiològiques, un gènere que intuïm menystingut i fins i tot oblidat per altres folkloristes de l'època.

Pel que fa als informadors, no en tenim gaires dades perquè molts dels reculls consultats no n'indiquen la font. Sí que ho fan Joan Amades i Antoni M. Alcover i cal dir que la majoria d'informants són dones de diverses contrades catalanes, en tant que els informants de sexe masculí són molt minoritaris. Aquest fet ens porta a pensar que les llegendes etiològiques sobre el naixement de Jesús eren relats molt propis de l'àmbit domèstic i usats habitualment en el procés d'aculturació dels infants.

\section{Vinculació amb el Nou Testament}

El Nou Testament és constituït per diversos llibres, entre els que destaquen els quatre evangelis. Els evangelis de Marc i de Joan no ens parlen del naixement del Salvador ni de la seva infantesa, atès que comencen la seva narració amb el baptisme de Jesús al Jordà. En canvi, Mateu i Lluc ens detallen la nissaga de Crist i n'expliquen l'anunciació, els dubtes de Josep, l'anada a Betlem, el naixement, l'adoració dels pastors, l'arribada dels Reis Mags, els temors i les ordres d'Herodes, la matança dels innocents, la fugida a Egipte i la tornada cap a Natzaret. Tant Mateu com Lluc són breus i sintètics en les seves explicacions i, tot i que forneixen les informacions cabdals sobre les quals es basa el cristianisme, no s'estenen en detalls ni informacions secundaries. És sobre aquest canemàs narratiu, en el qual no es pot ignorar l'aportació dels anomenats «evangelis apòcrifs», que la musa popular ha anat teixint una complexa xarxa llegendària molt extensa i variada que acompleix diversos objectius, entre els quals podríem destacar:

I. La magnificació i mitificació de les figures evangèliques, especialment de Jesús i de Maria, però també de Josep i de forma més secundària de Joan Baptista i dels Reis d'Orient.

2. L'ordenació i la classificació del món natural, sobretot la flora i la fauna, en éssers positius i beneficiosos o bé negatius i malignes segons la seva relació amb els personatges dels evangelis i les seves vicissituds.

3. L'explicació de determinats fets o costums socials o la invenció d'alguns objectes també per la seva relació amb els protagonistes dels evangelis.

El llegendari que estudiem constitueix una ampliació popular dels textos bíblics bàsicament orientada a explicar les característiques de l'entorn natural, i en

3. Per les mateixes cartes, veiem com Amades — amb l'ajut inestimable d'Anderson- catalogava el seu corpus rondallístic segons el sistema de classificació internacional AarneThompson. 
menor mesura social, partint d'unes suposades actuacions específiques dels éssers que les protagonitzen i desenvolupades a través d'un prisma moral i ideològic determinat. Si ordenem les llegendes segons una seqüència cronològica coherent amb la biografia de Jesús, podríem establir el següent esquema de temes, dels quals n'indicam la correspondència amb els Evangelis de Lluc i de Mateu:

I. L'anunciació a Maria i la revelació a Josep (Lc I,26-38 i Mt I,I8-24).

2. L'anada cap a Betlem (Lc 2,I-6).

3. El naixement de Jesús (Lc 2,7 i Mt I,I8-25).

4. L'adoració dels pastors (Lc 2,8-2O) i la dels Reis Mags (Mt 2,I-I2).

5. Presentació al temple i profecies (Lc 2,22-38).

6. La fugida cap a Egipte (Mt 2,I3-I5).

7. La tornada a Natzaret (Mt 2,I9-23).

8. La infantesa de Jesús (Lc 2,39-52).

Encara que el nombre de llegendes sobre el tema que tractem és molt alt, la majoria s'agrupen en dos moments clau: el naixement a Betlem i el camí de la fugida cap a Egipte. Aquests són els dos nuclis narratius principals en el llegendari, mentre que els altres esdevenen secundaris o complementaris. Un gran nombre de llegendes ens expliquen les característiques o funcions actuals d'animals i plantes del nostre entorn segons la seva participació en aquests episodis datats dos mil anys enrere. Generalment, les actituds positives dels éssers vius envers la Sagrada Família són premiades, i les negatives, castigades. Però caldrà fer-ne una anàlisi més detallada.

\section{Els personatges i els arguments}

La galeria de personatges es pot dividir en dos grans grups: els personatges evangèlics i els que no ho són pròpiament. Entre els primers hi ha dos protagonistes indiscutibles: Jesús i Maria, en tercer lloc cal situar sant Josep i després, de manera puntual, apareixen els Reis d'Orient, els pastors, Herodes i els seus soldats i alguns altres que trobem esmentats en funció del seu ofici: sabaters, ferrers i hostalers. L'altre grup de personatges el conformen una extensa relació d'animals i plantes personificats — generalment de l'entorn domèstic, però també de silvestres— que d'una manera o l'altra es relacionen amb els anteriors, de forma positiva o negativa.

Maria adopta un rol extraordinàriament actiu. Beneeix i maleeix plantes i animals segons pertoqui, amb promptitud i decisió. Sovint aquestes accions es presenten mitjançant fórmules rimades que emfasitzen el discurs i el fan més apte per ser recordat. Cal tenir en compte, també, que el vers té a les societats tradicionals algunes connotacions de sacralitat, i que les oracions de la tradició cristiana són versificades. Vegem-ne alguns exemples: 
Per què la pastorella és tan graciosa?

La pastorella va seguir la Sagrada Família i no la va deixar mai per a res, saltant de branca en branca. De tant en tant, aixecava el vol i inspeccionava si venien els soldats del rei Herodes, per tal de poder prevenir la Mare de Déu que el perill s'acostava i que tingués temps de poder-se amagar. Per aquest gest generós, la Mare de Déu la va beneir i li va dir:

-Pastorella, pastorella,

de tots els ocells

tu seràs la més bella.

I d'aleshores li ve a aquest moixonet la seva gràcia i gentilesa.

Segons Margarida Marginet, de Riu (I918) (Amades I950: 932).

Per la seva banda, el nen Jesús adopta un rol semblant al de Maria —reparteix premis i càstigs- però en menor mesura. Això es pot explicar perquè es tracta d'un nadó o un infant, i qui el protegeix i en té cura és sa mare; per tant, ella és qui ha d'organitzar i ordenar l'entorn que l'acull. Però també és un reflex i alhora una justificació etiològica de l'extraordinari paper de Maria a la pietat popular cristiana catòlica i de la importància del rol femení en aquestes llegendes, de les quals les dones són principals transmissores. Vegem-ne una on és el nen Jesús qui actua com a demiürg:

Per què les granotes són escuades?

A les granotes xerraires, que mai no callen, quan va néixer Jesús els va donar per no cantar, precisament aleshores que van parlar i van cantar totes les bèsties. Per aquesta prova de desafecte al Messies, van perdre la cua, que era el millor ornament que tenien, i van restar estranyes com són avui.

Recollida de boca d'Antònia Camps, de Reus, I9I8 (Amades I950: 948).

I aquesta altra:

Una altra del que diu la rosseta

Agraït el Jesuset a la rosseta per haver-li donat les seves plometes per a ferli el jacet més tou, li concedís la gràcia que el seu marit l'ajudés a covar els ous, com no ho fa gairebé cap més ocell. Quan la rosseta cova, a l'hora de menjar, hi va el seu marit i molt amorosament li diu:

- Vés a dinar,

vés a dinar.

I ella s'aixeca per anar a menjar i perquè els ous no es refredin s'hi ajoca ell.

Contada per Maria Cot, de Das (I935) (Amades I950: 968).

Josep té un paper més secundari, però tanmateix protector. L'anacronisme és evident en molts dels relats, sobretot quan es parla d'utensilis, festivitats, costums, jocs, etc.

Pel que fa als temes i arguments més reiterats, sens dubte el que presenta un major nombre de variants i versions recollides és el que fa referència a l'esterilitat de la mula. En tots els casos, l'esterilitat d'aquest animal —que és conseqüència de la seva naturalesa híbrida- s'explica com un càstig pel seu comportament a 
l'hora d'escalfar Jesús a la cova de Betlem. També trobem diversos textos que expliquen perquè dels tres reis d'Orient n'hi ha un amb la barba blanca, com a conseqüència d'un càstig per no haver guardat el respecte degut als seus companys de més edat.

\section{Els relats: estructures i funcions}

A partir de l'eix temàtic germinal dels evangelis es generen aquestes formulacions llegendàries — que sovint poc o res tenen a veure amb allò que s'indica a les Sagrades Escriptures- i que solen presentar les estructures habituals de les llegendes etiològiques. Cal tenir present que els evangelis, per la seva presència constant en la formació religiosa cristiana, eren coneguts per tothom des de les primeres edats. A la litúrgia, en els sermons, en les prèdiques, en els llibres piadosos i devocionaris, en els goigs que es cantaven en festes assenyalades, en el catecisme i la doctrina els principals episodis de la vida de Jesús constituien una pedra angular de l'educació religiosa i moral. I també era constant i reiterada la seva presència en la iconografia: retaules, relleus, quadres, escultures, capitells, il.lustracions de devocionaris, estampes... El Naixement és uns dels motius icònics més poderosos de la tradició cristiana. Per tant, per la paraula i per la imatge, els episodis evangèlics esdevenien referents ben coneguts sobre els quals era fàcil construir una xarxa de tradicions llegendàries que els complementaven i alhora els feien pròxims, entenedors i gairebé gosaríem dir que casolans, domèstics. I des d'aquest punt de vista, el fet que la major part d'informants siguin dones pren tot el seu sentit, atès que sobre elles requeia en bona part el procés d'inserció dels infants en la cultura pròpia i també la seva formació en els valors cristians, sense oblidar el pes de les supersticions en tots aquests processos, les quals sovint es presenten amb un vernís de religiositat.

L'estructura assenyalada per l'estudiosa Marlène Albert-Llorca (I99I: 2I) per als relats etiològics és la que presenten la majoria de les llegendes que analitzem. La podríem resumir en tres punts:

A. Posada en escena i presentació de l'objecte i dels personatge que intervenen en el procés.

B. Explicació de la causa que ha permès la creació de l'ésser o l'objecte o l'adquisició de les seves característiques.

C. La justificació i la validació empírica del relat en relació amb l'estat actual. La cloenda sovint confirma (de manera retòrica) la veracitat del que la narració explica.

Aquest funcionament estructural és fàcilment constatable en aquest exemple, en el qual cada paràgraf correspon a una de les parts assenyalades:

Com és que tots es dissabtes fa sol

La Puríssima rentava els dissabtes sa robeta del Bon Jesuset, i llavò l'estenia defora perquè eixugàs.

Es sol, si estava tapat, ja ho crec, tot d'una se destapava, i jzas! Ja tenia eixuta sa robeta, i la Puríssima ben aviat a entrar-la. 
D'aquesta manera es sol s'avesà a destapar-se tots es dissabtes, per ennigulat que estigués; i per això és que es dissabtes, sia així com sia, sempre en fa una retxeta, de sol.

(Alcover I936-72, tom 5: IO).

En el nostre treball titulat «Traditional balearic folktales associated with the Old Testament: types and structures» (Valriu 2OI3: 2I3-225) demostràrem com —a partir de la proposta global d'Albert-Llorca- era possible articular les estructures de les llegendes catalanes relacionades amb l'Antic Testament en quatre tipologies. Ara usarem aquesta mateixa proposta per comprovar si resulten també funcionals en les llegendes vinculades al Naixement.

\subsection{La confrontació bé-mal}

En algunes de les llegendes estudiades l'estructura indicada es desenvolupa a partir de la confrontació que s'explicita en aquest binomi:

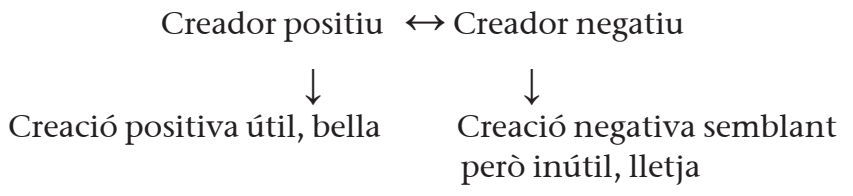

Aquest és el cas, per exemple, de la llegenda titulada «Una altra de com fou feta l'oreneta i la rata-pinyada» (Amades I950: 893) en la qual s'explica com el diable en forma d'infant desafià Jesús a veure qui faria l'ocell més bonic. Jesús —dels encenalls de la fusteria - va fer l'oreneta i el diable — amb penes i treballs — va fer la rata-pinyada de fang. És, però, una estructura poc freqüent en aquestes llegendes, que tracten més de característiques i qualitats que no del moment de la creació. Tampoc no hi trobem la variant estructural del creador positiu que obté uns resultats positius i que, en deixar la creació en mans d'un ajudant, aquest s'equivoca i els resultats obtinguts són defectuosos (Valriu 2OI3: 22I).

Dins aquest mateix grup podríem classificar les llegendes que únicament presenten la primera part del binomi. És a dir, a partir del contacte o la relació amb la divinitat es crea una nova realitat de caràcter positiu que és bella, agradable o útil. Com a exemples podríem esmentar les roses i els lliris blancs, que són així perquè foren esquitxats per la llet del pit de la Mare de Déu; el botonet daurat de la margaridoia, que ve d'una besada de l'infant Jesús; la fragància de les nadales, que es desvetllà en ser olorades per la Mare de Déu; les roses de Jericó, que germinaren d'unes gotes de llet del pit de Maria, o les flors anomenades «gota de sang», que sorgiren de gotetes de sang del peu de Jesús; els gessamins que ornaren el camí cap a Egipte, etc. ${ }^{4}$ Vegem-ne una en la versió que aporta Joan Amades:

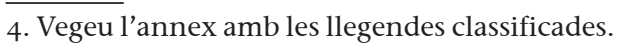


Per què l'ase és l'única bèstia que té la facultat de riure

L'ase de l'establia, en adonar-se de la gran ventura que havia tingut de veure néixer Jesús, va tenir una alegria tan gran que no sabia el que li passava i tot era saltar i botre de goig. Jesús li va voler premiar tanta joia i li concedí el do de poder riure, de què no gaudeix cap altra bèstia.

Recollida de boca d'Elvira Messeguer, de Barcelona (I9I8) (Amades I950: 9I7).

\subsection{Premis i càstigs}

Aquesta forma és, de molt, la més habitual en aquestes llegendes. Es desenvolupa en un gran nombre de casos a partir d'una mateixa estructura, però en positiu i en negatiu:

$$
\begin{aligned}
& \text { Ajut } \rightarrow \text { Premi } \rightarrow \text { Nova realitat positiva [finalitat moral o descriptiva] } \\
& \text { Infracció } \rightarrow \text { Sanció } \rightarrow \text { Nova realitat negativa [finalitat moral o descriptiva] }
\end{aligned}
$$

En el primer grup hi anirien els relats que podem considerar «en positiu» en els quals allò que s'obté és un do o una gràcia per les accions fetes o les actituds demostrades i que són nombrosíssims. A tall d'exemple en citarem uns quants:

Referits a característiques d'animals: l'agradable olor del mesc, els bous estelats, el llum de la cuca de llum, l'alè calent de la vaca, l'oïda fina de les oques i el seu coll llarg, el bec fort del trencalòs, la gràcia de la pastorella, el cant del rossinyol, el vol segur de l'oreneta, el xiular i cantar del merlot, la capacitat de la busqueta per a camuflar el seu niu, la manyagueria dels coloms, la rialla de l'ase, el color daurat de la rosseta, el respecte degut a les someres que tenen una creu damunt l'esquena, la perfecció del niu del capsigrany, etc. Vegem-ne una en la versió que aporta Joan Amades:

\section{Per què les oques tenen l'oüda tan fina?}

Així que l'oca va saber que Jesús era nat, se'n va anar amb una grossa nierada de titones cap a l'establia, perquè el Nadó hi jugués. I amb tota la collada va instal-lar-se a un reconet de la coveta; per tal de poder tenir cura de les seves oquetes i fer-les jugar amb el Jesuset, sempre que ell ho volgués. I heus ací que uns lladregots, de nit i d'amagat, volien arribar fins a la cova per robar les joies i els rics presents que els tres Reis havien portat al bon Jesús. L'oca va sentir el soroll molt abans d'arribar els lladres a la cova; es va posar a cridar i va despertar Josep i Maria, i els lladres, en veure's descoberts, van fugir. El Jesuset va concedir a l'oca el do de tenir una oïda molt fina, perquè sempre més, des de ben lluny, pogués percebre el soroll més petit, i també li va donar el do de poder viure sense dormir, per poder estar sempre amatent i vigilant. I per tot arreu les oques fan de guardes de les pagesies tant com els mateixos gossos.

Recollida de boca de Rosa Dansa, de Barcelona (I9I8) (Amades I950: 937) 
Referits a característiques de plantes: la virtut de la fusta d'avellaner, el poder curatiu de la malva, del poliol, de la camamilla, de la sàlvia, de la ceba, del bàlsam; el bon sabor del julivert, la floració hivernenca de la rosa de nadal, la fragància de les nadales, les virtuts de l'oli, els colors i la intensa floració del romaní, etc.

El segon grup — no tan extens com el primer- correspondria als relats «en negatiu», en els quals el resultat final és conseqüència d'un càstig. Vegem-ne alguns exemples:

Referits a característiques d'animals: la feresa de l'ós, l'esterilitat de la mula, la impossibilitat de volar del pica-soques, la manca de cua de les granotes, la fam insaciable dels cavalls, la impossibilitat de caminar de la llagosta, la por del mussol petit que li facin malbé els ous i el niu.

Referits a característiques de plantes: la coïssor de l'ortiga, la mala consideració del vern, la fetor dels naps, el poc valor de les canyes, el cap socarrat del jonc, el que la menta no faci fruit, les punxes de la romeguera, etc. Vet ací un exemple:

Per què el pi té les branques tan altes

El pi era un arbre amb un brancatge abundantíssim que s'estenia per tot el tronc fins arran de terra, tan espès que hom podia bé soplujar-se entre el brancatge com si fos una barraca o una casa. La Mare de Déu va trobar-se gairebé atrapada per la tropa, va acostar-se a un pi per amagar-se, però el pi orgullós i de mal cor, va aixecar tot seguit el brancatge tronc amunt i va restar despullat de la part baixa. La Mare de Déu va maneir-lo i li va dir:

-Pi desventurat seràs,

que ni tu ni tota la teva descendència

mai més no brotaràs.

I per això, segons diu la gent, el pi no brota i es manté encara amb les branques al cim del tronc i tot aquest nu.

Recollida de boca de Caterina Cordumí, de Barcelona (I9I8) (Amades I950: IO05).

En algunes llegendes apareixen alhora les dues estructures de manera consecutiva, generalment primer la negativa i després la positiva. Un ésser presenta una conducta negativa envers la Sagrada Família i seguidament un altre de semblant —davant la mateixa mancança o problema - la presenta positiva. El primer és castigat, i el segon, premiat. Aquesta estructura és també molt freqüent en un gran nombre de tipus rondallístics. Per exemple, la llenya del vern només serveix per cremar perquè Maria li demanà ajuda i aquest la hi negà; davant la mateixa situació l'arç l'ajudà i per això és molt apreciat (Amades I950: IOI6). ${ }^{5}$ De la mateixa manera s'explica l'existència de la romeguera vera i la romeguera borda o els noms contraposats de la sàlvia (salvadora) i de la menta (mentidera) (Amades I950: IOII) i moltes d'altres. A tall d'exemple, podem aportar aquesta:

5. Vegeu «Per què el vern només serveix per cremar i l'arç va pels altars» (Amades I950: Ioo3IOO4). La llegenda inclou una fórmula rimada de benedicció i una de maledicció, posades en boca de Maria. 
Per què uns ocells són bons per a menjar i d'altres no

Els ocells van acudir en gran munió a la cova, i el Jesuset se'n va agradar i va demanar que hi acudissin tots. Molts dels qui no hi havien anat espontàniament ho varen fer davant el requeriment diví, però d'altres van fer l'orni i no hi van anar. L'Infantó va premiar tots els qui l'havien anat a veure i els va concedir que fossin agradosos de menjar, suculents i estimats per l'home, i va castigar els altres a no ser mengívols i que la seva carn fos ingrata. Tots els ocells, doncs, que els caçadors no cerquen, tals com la garsa, el mussol, la puput, el cucut, l'òliba, el corb i tots els ocells de presa, entre molts altres, foren dels que no varen atendre al desig del Jesuset.

Recollida de boca de Ramona Prats, de Sabadell (I922) (Amades I950: 94I).

De vegades, el que s'obté és el nom, l'apel-latiu. Aleshores la llegenda explica per què tal animal o planta s'anomenen d'aquella manera. Aquests és el cas de «Per què ara anomenen vesper al falcó» (Amades I950: 926-927) i de les llegendes que expliquen l'origen del nom d'ocells de nom compost com el gratapalles, el caganaps i el papamosques o de plantes com la menta. També de les plantes que al seu nom afegeixen l'epítet «de la Mare de Déu» com les roses de la Mare de Déu o els lliris de la Mare de Déu. Un cas especial d'etimologia popular és el de les llegendes que expliquen el nom en funció d'una metamorfosi o d'una confrontació. Així, els soldats d'Herodes que corrien de pressa tot encalçant la Sagrada Família foren transformats en camamil.la (cames mil) (Amades I950: 993) i el nom del julivert vindria de joliu + verd en oposició a la menta, que va ser traïdora (mentidera):

Per què el julivert és tan gentil

Diuen que el julivert, en sentir les paraules mal intencionades de la menta, va apressar-se a dir:

-Dius mentida, mentidera,

dius mentida

en mort i en vida.

La Mare de Déu va beneir el julivert, que fins aleshores era una herba sense gràcia ni suc ni bruc, i des d'aleshores va prendre la gentilesa i la graciosa verdor que té, com també el gust delicat que li dóna fama de les més estimades per als bons guisos. Per efecte de la gràcia i de la verdor que va cobrar, la gent va començar a anomenar-lo «joliu i verd», mots que juntets han fet el nom de «julivert», que avui se li dóna, puix que abans se l'anomenava d'altra manera (Amades I950: IOII).

Notem que la presència reiterada d'aquestes estructures basades en la correlació «ajut-premi» i «infracció-sanció» no és casual. Les llegendes que analitzem presenten aquesta estructura perquè és la més funcional per aconseguir els objectius que es proposen i que podríem sintetitzar en:

A. Fornir - d'una manera senzilla i entenedora- pautes de conducta entre els qui les escolten i molt especialment entre els infants com a receptors prioritaris. Es tracta d'inculcar la idea que les conductes negatives sempre són durament castigades i les positives premiades amb escreix. 
B. Ordenar el món segons la suposada utilitat o no de determinades plantes i animals per a la vida humana, donant una fonamentació religiosa a aquest fet, i, per tant, fent-lo inqüestionable.

C. Argumentar el perquè d'un determinat nom a una planta o animal (objectiu de justificació onomàstica), tot i que aquest objectiu podria ser considerat una formulació diferent de l'anterior, una forma derivada.

\subsection{Les llegendes mimològiques}

Un gran nombre de llegendes del nostre corpus inclouen mimologismes, especialment les referides als ocells i, en menor mesura, a altres animals. No les considerarem estructures diferenciades, perquè la majoria es poden encabir en els models estructurals que hem desenvolupat, però mereixen una atenció especial per la importància argumental i estilística de la frase mimològica en el context narratiu. Sense afany d'exhaustivitat, podem esmentar que hi ha llegendes relacionades amb el Naixement que expliquen què diuen en cantar la titeta sorda, el caganaps, la calàndria, el gall, el bou, el be, l'ase, el teixidor, el raspinell, la cueta llarga, l'ermità, la primavera, la cadernera, la rosseta, el grífol, el roquerol, l'oreneta, el gaig i una sobre els ocells en general. Les frases atribuïdes als animals són molt diverses. De vegades repeteixen el que digueren en presència dels personatges evangèlics, com en aquest exemple:

\section{Del que diu el raspinell}

Fou un dels primers ocellets que acudiren a la cova per adorar el Nadó, i mai no va parar de voleiar per la vora dels qui l'anaven a adorar, per tal de festejar-los i de fer-los moixaines. Maria el beneí i li concedí el do de no fer-li por la gent. I quan canta, tot tou i satisfet ho explica:

-Sóc beneït, sóc beneït,

no em fa por la gent,

no em fa por la gent.

Contada per Maria Cot, de Das (I935) (Amades I950: 9I7).

Altres vegades els animals repeteixen el resultat de la seva recompensa o el seu càstig. En tots els casos, la seva frase és recordança del moment singular de relació amb la divinitat, un moment que — per bé o per mal- marcà les característiques de tota l'espècie. Les frases sempre es presenten en fórmules rimades que - per la seva fonètica - recorden el cant de l'ocell en qüestió, encara que aquests tipus de llegendes - per ser explicades de manera reeixida - necessiten la competència d'un bon narrador que conegui el cant de l'animal i el pugui fusionar amb la frase, articulant-la de forma convincent. A tall d'exemple podem citar que el grífol obtingué un càstig per dir de Jesús «—És bord! És bord» (Amades I950: 975) i que el gall anuncià «一Jesús és nat! Jesús és nat! Jesús és nat!» i per això li va ser concedit el do de ser el que canta més fort (Amades I950: 997).

\subsection{Altres materials}

La resta de materials que trobem en el corpus estudiat presenta un caràcter més dispers, de vegades amb un desenvolupament narratiu més complex i elaborat 
o amb la presència de motius narratius propis de les rondalles. En el context de la fugida a Egipte, trobem un gran nombre de narracions entre les quals destaca la que desenvolupa l'argument de la Mare de Déu i el sembrador, que trobem en diferents reculls i que aglutina diversos motius i ítems llegendaris. L'argument esquematitzat és el següent:

I. Els soldats d'Herodes perseguien la Sagrada Família i arribaren a un camp on un pagès acabava de sembrar blat.

2. Maria li manà que anés a cercar la falç per segar-lo.

3. El pagès obeí sorprès i en tornar el blat era a punt de segar.

4. En va fer una gran garba i els perseguits s'hi amagaren darrere.

5. Quan els soldats arribaren demanaren al pagès si havia vist els fugitius, ell va dir que sí, que els havia vist quan sembrava el blat. Els soldats se n'anaren, tot pensant que havien perdut el rastre, perquè si el blat ja era segat devia fer molts de mesos que el pagès l'havia sembrat.

6. Però la menta els acusava (fórmula rimada).

7. Maria la maleí a ser llenguallarga (les fulles de la menta semblen llengües) i a ser símbol de la mentida i a florir però no granar.

Sobre aquest argument trobem diverses variants segons el recull. El que ens interessa destacar és el punt 5, que coincideix amb la contarella catalogada com ATUi38IE (Old Man Sent to the School). Algú que fa una activitat inusual (en aquest cas poder segar un blat acabat de sembrar) és interrogat per un altre que busca quelcom (en el nostre cas els soldats que busquen els fugitius). En escoltar la resposta a la seva pregunta, abandonen la recerca perquè hi ha un decalatge temporal evident (la família que el pagès va veure passar quan sembrava no pot ser la que els soldats busquen ara, perquè el blat ja està segat i per tant ha d'haver passat molt de temps entre una acció i una altra). També a la llegenda titulada «Per què el romaní fa flors blanques i blaves» (Amades I950: IOI3) trobem inserit el tipus catalogat com la contarella ATU I38IB, una variant de l'anterior. El context és el mateix, la persecució durant la fugida cap a Egipte. Maria i Jesús s'han amagat sota un romaní, Josep és interrogat pels soldats i dóna respostes absurdes a les preguntes que li formulen, de manera que el prenen per boig i segueixen el seu camí sense fer-li cas i sense adonar-se que són a la vora dels qui busquen (Amades I950, гоI3). ${ }^{6}$

Aquests exemples posen de manifest la liquiditat de les fronteres entre els gèneres de la literatura oral i la fusió de materials que comporta l'oralitat. També els arguments d'algunes de les llegendes que comentem es troben en forma de nadales o de cançons de bressol o bé de tradicions o supersticions, atès que els ar-

\footnotetext{
6. Vegeu el diàleg que s'estableix entre sant Josep i els soldats:

«-Escolteu, bon home, ¿heu vist passar per ací una dona amb un noiet al braç?

-Fa mal temps per a pasturar el bestiar. No trobo gens d'herbeta per a pasturar aquesta somereta.

-No és pas això el que us preguntem. ¿Sabeu si han passat per ací una fadrineta amb una criatura al braç?

- Tan matí fa un fred que pela i no sóc a temps a bufar-me els dits.

Davant unes respostes tan desbaratades els soldats el van prendre per un beneit i el van deixar estar i van seguir el seu camí» (Amades I950: IоI3).
} 
guments populars adopten una o altra forma, una textura determinada, en funció d'un ampli espectre de possibilitats contextuals.

\section{Conclusions}

Indicarem breument les conclusions a què ens ha portat aquesta recerca:

I. Constatar l'abundància i varietat d'aquestes llegendes en la tradició de la literatura oral catalana i la seva vinculació amb el món femení. Les dones sembla que són majoritàriament les depositàries d'aquestes tradicions i les encarregades de difondre-les.

2. Remarcar la vinculació amb els evangelis canònics i col-lateralment també amb els apòcrifs. Constitueixen una amplificació poètica — sovint de to senzill i domèstic i de caràcter moral— d'allò que expliquen les Sagrades Escriptures, alhora que demostren una gran capacitat d'observació i de coneixement del medi natural per part dels creadors i narradors d'aquest llegendari.

3. Destacar la funcionalitat evident d'aquests materials, tant des del punt de vista explicatiu i didàctic com poètic. Aquesta funcionalitat es fa palesa en la claredat i simplicitat de les estructures sobre les quals s'articulen i en el desenvolupament narratiu breu i concís. Les estructures són bàsicament tres:

Creador positiu [creació positiva, útil, bella] $\leftrightarrow$ Creador negatiu [semblant però negativa, inútil, lletja]

Ajut $\rightarrow$ Premi $\rightarrow$ Nova realitat positiva [finalitat moral o descriptiva]

Infracció $\longrightarrow$ Sanció $\longrightarrow$ Nova realitat negativa [finalitat moral o descriptiva]

4. La importància i abundància dels mimologismes. En les llegendes que els inclouen, d'una banda, són la peça clau entorn de la qual gira l'argument i, de l'altra, sovint tenen un contingut poètic i simbòlic important. Responen a un desig humà ancestral: poder entendre els animals i comunicar-se amb ells, poder interpretar què diuen.

5. Aquests relats són un punt de confluència de gèneres, atès que poden presentar estructures i motius propis de les rondalles i també compartir arguments amb peces de poesia popular.

En conjunt, podem dir que ens trobem davant uns documents de narrativa popular interessantíssims tant per la seva vàlua literària intrínseca com per les seves connexions amb les creences, el costumari, les formes de vida, l'ecosistema i —en general - la cosmovisió de les societats tradicionals. El progrés científic ens aporta la visió objectiva de la realitat, el llegendari ens aporta la visió subjectiva, animista, simbòlica. No són enfocaments que s'excloguin, sinó que es complementen si els sabem percebre i acceptar des d'una mentalitat oberta i inclusiva. És per això que conservar i difondre aquests materials, donar-los visibilitat, és una contribució modesta però valuosa a l'arquitectura que ens conforma i articula com a societat, com a país amb fondes arrels, amb capacitat per expressar amb símbols i metàfores la nostra manera d'entendre el món, la nostra cultura. 


\section{Referències bibliogràfiques}

AADD (I992): La Bíblia de Montserrat. Andorra: Casal i Vall.

Alcover, Antoni M. (I936-72): «Ecos de la vida de Jesús, Maria i Josep». Dins Rondaies Mallorquines d'en Jordi des Recó. Palma: Moll.

Albert-LlorcA, Marlène (I99I): L'ordre des choses. París: Éditions du C.T.H.S / Éditions du Comité des Travaux Historiques et Scientifiques.

AmADES, Joan (I950): «I. Tradicions explicatives». Dins Folklore de Catalunya: Rondallistica. Barcelona: Selecta, p. 859-IO27.

BELtran, Rafael (2007): Rondalles populars valencianes. Antologia, catàleg i estudi dins la tradició del folklore universal. València: Universitat de València.

BERTRAN, Pau (I996): El rondallari català. Barcelona: Alta Fulla.

CAMPS, Francesc (2007): Folklore menorquí: de la pagesia. Tom I. Maó: Institut Menorquí d'Estudis.

CASEPOnCE, Esteve (1972): «De Betlem al Calvari». Dins Rondalles. Barcelona: Balmes, p. I75-I8I.

CASTElló, Joan (2004): «Es bou i sa mula», «Sa menta», «Anar de comares». Dins Rondalles eivissenques de quan el Bon Jesús anava pel món. Eivissa: Institut d'Estudis Eivissencs, p. 38-42.

CERDÀ, Jordi Pere (I96I): «Les tres Maries». Dins Contalles de Cerdanya. Barcelona: Barcino, p. 45-50.

Coll, Pep (I993): «Plantes beneïdes». Dins Muntanyes maleïdes. Barcelona: Empúries, p. 307-308.

FERrER, Andreu (2009): «Per què fa sol tots els dissabtes», «Nius de cega», «Per què les mules no crien». Dins Llegendes de les Balears. Barcelona: Publicacions de l'Abadia de Montserrat, p. 284, 295-297.

GonZÀLEZ, Joaquim (I993): «Per què la mula no té fills?». Dins Rondalles del Baix Vinalopó: contes populars. Alacant: Aguaclara, p. I25-I26.

LLORENS, Sara: «Perquè els llobins amarguen», «Perquè la ploma dels aucells no serveix i la carn sí». Dins Llegendes alacantines, I929 [manuscrit conservat a la carpeta B-I56 de l'Obra del Cançoner Popular de Catalunya; edició a cura de Joan BORJA (en premsa)]

ORIOL, Carme (2OI4): «Édition de la correspondance entre les folkloristes Walter Anderson et Joan Amades». Estudis de Literatura Oral Popular 3: 49-84.

OrIOL, Carme; Josep M. PUjOL (2003): Índex tipològic de la rondalla catalana. Barcelona: Generalitat de Catalunya.

- (2008): Index of catalan folktales. Folklore Fellows' Communications 294. Hèlsinki: Suomalainen Tiedeakatemia.

RondCat: cercador de la rondalla catalana. Arxiu de Folklore, Departament de Filologia Catalana de la Universitat Rovira i Virgili <http://www.rondcat.arxiudefolklore.cat $>$ [data de consulta: setembre de 20I5]

QUiNTANA, Artur (I979): «Per què les mules no poden criar?», «Per què el cap de la perdiu no es pot menjar». Dins Bllat colrat. Calaceit: I. E. Altoaragoneses / I. E. Baix Cinca / I. E. Ilerdencs / D. G. d'Aragó, vol. I, p. I6I. 
SANTos, Aurelio (1993): Los Evangelios apócrifos. Madrid: Biblioteca de Autores Cristianos.

UTHER, Hans-Jörg (2004) [ATU]: The types of international folktales. A classification and bibliography. Based on the system of Antti Aarne and Stith Thompson. 3 vols. Folklore Fellows' Communications 284-285-286. Hèlsinki: Suomalainen Tiedeakatemia.

VALRIU, Caterina (20I3): «Traditional balearic folktales associated with the Old Testament: types and structures». Estudis de Literatura Oral Popular 2: 213-225.

\section{Annex}

En aquest annex s'hi indiquen els títols de les llegendes estudiades. Estan dividides en tres blocs: naixement, fugida a Egipte i infantesa. Cada bloc està dividit en relats de caràcter positiu (premis) i de caràcter negatiu (càstigs); dins cada bloc es distingeix entre llegendes que tracten sobre animals, plantes i altres. Les que únicament duen un número corresponen al recull de Joan Amades (I950), les que no són d'aquest recull indiquen el nom del recol-lector seguit del títol de la llegenda. Les llegendes que inclouen una frase mimològica estan assenyalades amb un asterisc $\left(^{*}\right)$.

\section{Llegendes sobre el naixement}

\subsection{De caràcter positiu}

\subsubsection{D'animals}

770. De com fou creat el gat mesquer.

794. Per què hi ha bous estelats.

795. Per què els bous tenen una mà marcada damunt de les anques.

833. De què ve que la cuca de Sant Joan faci llum.

854. Dels tres dons concedits a la vaca.

856. Per què l'ase és l'única bèstia que té facultat de riure.

877. Per què la rosseta és de color daurat i li cauen tantes plomes.

882. Per què els gossos de presa no ataquen les persones que van nues.

892. De què ve que es caci la titeta sorda al so dels ferrerets.

895. Per què el blauet fa al niu al cau de la rata.

896. Per què ara anomenen vesper al falcó.

898. De què li ve el nom al gratapalles.

899. Per què el niu del teixidor sembla una mitja.

902. De què li ve el seu nom al caganaps.

905. Per què tots els ocells es reuneixen en família el dia dels Reis.

9I4. Per què el papamosques menja mosques i el formiguer formigues.

932. Per què el girapedres es pot menjar els ous dels altres ocells.

933. Per què el falcó pot mudar el color del plomatge.

936. Per què les oques tenen l'oïda tan fina.

937: Per què l'oca té el coll tan llarg.

938. Per què la pastorella segueix els sembradors.

946. Per què el trencalòs té el bec tan fort. 
952. Per què uns ocells són bons per a menjar i d'altres no.

953. Per què hi ha ocells de diferents colors.

* I009. Del que diu la calàndria.

${ }^{*}$ IO49. Un altre del que diu la rosseta.

* I05I. De com les bèsties la nit de Nadal van gaudir del do de la paraula.

${ }^{*}$ I052. Del que diu el teixidor.

${ }^{*}$ IO7O. Del que diu el raspinell.

${ }^{*}$ IO77. Del que diu la cueta llarga.

${ }^{*}$ I079. Del que diu l'ermità.

*I085. Del que diu la primavera.

*Io88. Per què el gall és l'ocell que canta més fort.

*IIO4. Del que diu la cadernera.

\subsubsection{Plantes}

II57. De que vénen les roses i els lliris blancs.

II75. De què ve que les ametlles facin llet a les dones quan crien.

II76. Per què la fusta d'avellaner té virtut.

II88. Per què és pecat cremar fusta d'àlber.

II89. Per què la fusta de xop no serveix per fer forques.

II9I. Per què el vern només serveix per cremar i l'arç va pels altars.

II99. Perquè la pomera és beneïda.

I2I7. De què ve la virtut remeiera de la malva.

I2I9. Per què el puniol [sic] té virtut remeiera.

I238. De què ve que la margaridoia tingui el botó daurat.

I240. Per què la rosa de Nadal floreix per Nadal.

I24I. Per què les nadales són tan oloroses.

I258. Per què l'oli té virtut remeiera.

Coll, Pep: Plantes beneïdes.

\subsubsection{Altres}

I262. Per què el rei Gaspar, essent el més jove, té els cabells blancs.

I263. Una altra de per què el rei Gaspar essent el més jove tenia els cabells blancs. I264. Per què els sabaters fan festa en dilluns.

I265. Per què els bons cristians mengen coca el dia dels Reis.

\subsection{De caràcter negatiu}

\subsubsection{Animals}

778. De com va ser creat el peix volador.

784. De com un gitano fou convertit en el cucut.

797. De què ve l'ós.

829. Per què la mula no fa mulats.

830. Una altra de per què la mula no fa mulats.

83I. Per què la mula llaura amb coixí.

883. Per què somniar gats porta desgràcia.

900. Per què el mussol petit cada dia muda els ous i els petits de lloc. 
935. Per què el pica-soques no pot volar.

947. Per què el trencapinyol sembla que sempre mastega.

952. Per què uns ocells són bons per a menjar i d'altres no.

977. Per què la sargantana és maleïda.

981. Per què les granotes són escuades.

*Iori. De què ve que la calàndria renegui.

* I048. Del què diu la rosseta.

*I078: Del que diu el grífol.

*IIo8. Del que diu el roquerol.

Castelló, Joan: Es bou i sa mula.

\subsubsection{Plantes}

II49. De com fou creada l'ortiga.

II9I. Per què el vern només serveix per cremar i l'arç va pels altars.

II92. Per què les bèsties fugen del vern.

I2Io. Per què els naps són fetosos.

\subsubsection{Altres}

I28I. Per què els forners i els ferrers no neguen mai la caritat. I282. Per què els hostals tenen per patrona a santa Marta.

\section{Llegendes sobre la fugida a Egipte}

\subsection{De caràcter positiu}

\subsubsection{Animals}

855. Per què hi ha someres que tenen una creu damunt l'esquena.

885. Per què no es perdrà mai la casta dels ases.

886. Per què l'ase és animal que s'alimenta del menjar més pobre.

887. Per què és més dolent caure de damunt d'un ase que d'un cavall.

888. Per què l'ase és beneït.

9I5. Per què el niu del corb no es mulla quan plou.

9I6. Per què hom té el capsigrany per toix i beneitó.

9I7. Per què el papafigues només menja figues.

9I8. Per què la pastorella és tan graciosa.

92I. Per què l'oreneta sap tant de volar i el rossinyol de cantar.

922. Per què les orenetes fan niu per les cases.

940. De què li ve al merlot que pugui xiular i cantar.

*945. Per què la cueta belluga contínuament la cua.

983. Per què és pecat matar l'aranya.

*998. El que diu l'oreneta.

IIOI. Per què no es troben nius de busqueta. 


\subsubsection{Plantes}

II52. De com fou creada la camamilla.

II53. De com foren creades la vara de Jessè i la marialluïsa.

II58. De com van florir les roses de Jericó.

II59. Unes altres de com van florir les roses de Jericó.

II6o. De com va florir la gota de sang.

II70. Per què les oliveres tenen les fulles girades.

II73. Per què és pecat cremar fusta d'ametller, de taronger, de pomera, de cirerer i de freixer.

II77. Per què l'avellaner i la canya són beneïts.

II78. Per què la palmera és beneïda.

I207: Per què en el blat s'hi veu la cara de Nostre Senyor.

I2I5. Per què la farigola s'anomena mantellet de la Mare de Déu.

I2I8. Per què el fonoll és beneït.

I22I. Per què el julivert és tan gentil.

I222. Per què la sàlvia s'anomena així i té virtut remeiera.

I224. Per què el grèvol pels innocents espurneja sang.

I227. Per què les punxes de floravia no punxen i els glans no fan mal per més que se'n mengin.

I23I. Per què el romaní té les flors blanques i les flors blaves.

I242. Per què hi ha romeguera vera i romeguera borda.

I243. Per què el lleçamí [sic] floreix vora dels camins.

I259. De com fou trobada la falç.

\subsection{De caràcter negatiu}

\subsubsection{Animals}

884. Per què el cavall és l'animal més menjador.

${ }^{*}$ 9I2. Per què el cap de la perdiu no es pot menjar.

913. Per què les plomes de la perdiu són maleïdes.

987. Per què la llagosta salta i no camina.

${ }^{*}$ IO32. Del que diu el gaig.

*IO34. Per què el gaig està sempre magre.

\subsubsection{Plantes}

II5O. De què ve que la reina de les flors només duri un dia.

II97. Per què el pi té les branques tan altes.

I202. Per què les canyes serveixen per mànecs d'escombra?

I205. Per què el jonc té el cap socarrat.

I220. Per què la menta floreix i no grana.

I233. Per què la xicoira creix a la vora dels camins.

242. Per què hi ha romeguera vera i romeguera borda.

Castelló, Joan: Sa menta.

\subsubsection{Altres}

I279. Per què l'ofici de mestre de cases és maleït. 


\section{Llegendes sobre la infantesa}

\subsection{De caràcter positiu}

\subsubsection{Animals}

774. Una altra de com fou feta l'oreneta i la rata pinyada.

775. De com fou creada la cadernera.

908. Per què és pecat matar els pardals.

920. Per què els colom són manyacs.

984. Per què per les festes de la Mare de Déu moren totes les puces.

*Ior2. Per què la puput posseeix la pedra de l'alegria.

${ }^{*}$ IO5O. Del que diuen els ocells.

\subsubsection{Plantes}

II54. De com foren creades les flors més boniques.

I200. Per què la taronja és daurada.

I208: De què ve que la ceba tingui virtut remeiera.

I2I3. De què ve la virtut remeiera del bàlsam.

I232. Per què el romaní floreix quatre vegades l'any.

I26I. De com fou trobada la serra.

I283. Per què no hi ha dissabte sense sol.

\subsubsection{Altres}

682. De què ve l'estel tarongeta.

Ferrer, Andreu: El Bonjesuset captant.

\subsection{De caràcter negatiu}

773. De com fou creada l'oreneta.

774. Una altra de com fou feta l'oreneta i la rata pinyada.

778. De com va ser creat el peix volador. 